\title{
Parental alcohol use disorders and alcohol use and disorders in offspring: a community study
}

\author{
R. LIEB,${ }^{1}$ K. R. MERIKANGAS, M. HÖFLER, H. PFISTER, B. ISENSEE \\ AND H.-U. WITTCHEN \\ From the Department of Clinical Psychology and Epidemiology, Max-Planck Institute of Psychiatry, Munich \\ and Clinical Psychology and Psychotherapy, Technical University of Dresden, Dresden, Germany; and \\ Genetic Epidemiology Research Unit, Yale University School of Medicine, New Haven, CT, USA
}

\begin{abstract}
Background. We examined the association between parental alcohol use disorders and patterns of alcohol consumption and DSM-IV alcohol use disorders in their offspring in a community-based sample of young adults.

Methods. Data are based on baseline and 4-year follow-up data of 2427 respondents aged 14-24 at baseline. Alcohol use and disorders in respondents were assessed using the Munich-CompositeInternational-Diagnostic-Interview with DSM-IV algorithms. Diagnostic information about parents was collected by family history information from the respondents, and by direct interview with one parent (cohort aged 14 to 17 years only).

Results. Although the association between maternal and paternal alcohol use disorders and nonproblematical drinking in offspring was minimal, there was a strong effect for the transition to hazardous use and for alcohol abuse and dependence; the effect of parental concordance for transition into hazardous use was particularly striking. Maternal history was associated with a higher probability of progression from occasional to regular use, whereas paternal history was associated with progression from regular to hazardous use. Parental alcoholism increased the risk for first onset of hazardous use and alcohol dependence between the ages of 14-17, and for an earlier onset of the alcohol outcomes in offspring. The impact of parental alcohol use disorders was comparable for male and female offspring.
\end{abstract}

Conclusions. Parental alcoholism predicts escalation of alcohol use, development of alcohol use disorders and onset of alcohol outcomes in offspring.

\section{INTRODUCTION}

Alcohol use and disorders are considered to be among the most prevalent public health problems, even in adolescence and young adulthood (Lewinsohn et al. 1996; Nelson \& Wittchen, 1998). The investigation of factors that place subjects at an increased risk of development of alcohol problems has been a major area of research during recent decades (for review see Hawkins et al. 1992; Weinberg et

1 Address for correspondence: Dr Roselind Lieb, Max-Planck Institute of Psychiatry, Clinical Psychology and Epidemiology Unit, Kraepelinstrasse 2, 80804 München, Germany. al. 1998; Swadi, 1999). One important risk factor that has been studied extensively is alcoholism in parents. Although some studies have yielded controversial findings (Pandina \& Johnson, 1990; Neff, 1994), the vast majority have shown a strong association between alcohol use and disorders in parents and offspring (Merikangas et al. 1985; Russell et al. 1990; Sher et al. 1991; Chassin \& Barrera, 1993; Knop et al. 1993; Mathew et al. 1993; Reich et al. 1993; Bidaut-Russell et al. 1994; Weinberg et al. 1994; Schuckit \& Smith, 1996; Kendler et al. 1997; Tarter et al. 1997; Alterman et al. 1998; Merikangas et al. 1998a, b; Dierker et al. 1999; 
Hill \& Yuan, 1999; Hill et al. 1999, 2000). Most of these studies recruited their samples from treatment centres. As Kendler \& Roy (1995) have shown for depression, families sampled in clinical settings may differ in their familial characteristics from families who do not seek help. Therefore, the familial nature of alcoholism may differ among families recruited in treatment centres from those identified in the general community. Thus, to avoid potential overestimation of effects by 'familial clustering', the familial nature of alcohol problems should also be investigated in community-based samples (Russell et al. 1990; Mathew et al. 1993; Kendler et al. 1997) in order to examine the effects in potentially less severe cases and to allow for the generalizability of such clinical findings.

Previous clinical research also addressed important issues concerning the first manifestation and progression of problematical drinking in the offspring of affected parents. Thus, for adolescents of fathers in treatment centres, Chassin \& Barrera (1993) showed that there was a greater increase in alcohol use over time than among adolescents without alcoholic parents. Focusing on age of onset of drinking and alcohol problems, Hill \& Yuan (1999) as well as Hill and other colleagues $(1999,2000)$ recently demonstrated that children with a positive family history of alcoholism have an earlier onset of regular drinking and an earlier development of substance use disorders than children without a family history of alcoholism. Using a quantitative estimate of familial loading for alcoholism (number of first- and second-degree relatives affected), they further demonstrated that highrisk children with a greater familial density of alcoholism have a higher risk for early alcohol initiation than those with lower familial density of alcoholism. Evidence from clinical samples suggests that a family history of alcoholism not only increases the risk of alcohol problems in the offspring, but also affects the age of the first manifestation of such problems, and of early drinking patterns. Research with communitybased samples would enable investigators to gain information regarding the external validity of the findings. It is important to study subjects close to the period of greatest risk for the onset of alcohol use as well as alcohol use disorders (Kandel, 1984; Nelson \& Wittchen, 1998) in order to obtain reliable information about early developmental stages of problematical drinking and abuse and dependence syndromes.

This paper examines the parent-offspring association in alcohol use and disorders in a prospectively assessed representative community sample of adolescents and young adults for whom diagnostic information about alcohol use disorders in both parents was collected. The following questions will be addressed: (1) To what degree is a parental history of alcohol use disorders associated with alcohol use in offspring in a community sample?; (2) Is a history of parental alcohol use disorders associated with any particular patterns of progression of alcohol use in offspring?; (3) What is the magnitude of the association between a parental history of alcohol use disorders and the occurrence of DSM-IV alcohol abuse and dependence in offspring?; and (4) Do children with affected parents differ in their age of onset of alcohol use and alcohol use disorders from children whose parents are not affected?

\section{METHOD}

\section{Design}

The data presented come from the Early Developmental Stages of Psychopathology Study (EDSP). The EDSP is a prospective longitudinal study designed to collect data on the prevalence and incidence, familial and other risk factors, co-morbidity and course of substance use and other mental disorders in a representative sample of 3021 subjects aged 14-24 at baseline. The study consists of a baseline survey, two follow-up surveys, and a family history component. Detailed descriptions of the EDSP design and field procedures are reported elsewhere (Wittchen et al. $1998 a, b$; Lieb et al. $2000 a, b)$.

\section{Community respondents}

The EDSP sample was drawn randomly from the 1994 government population registers of residents in metropolitan Munich and the surrounding counties with an expected age range for the sampled subjects between 14 and 24 at the time of the baseline interview in 1995. As the study was designed as a longitudinal panel with special interest in early developmental stages of psychopathology, 14-15-year-olds were sampled at twice the probability of people 16-21 years of 
age, and 22-24-year-olds were sampled at half the probability of the 16-21-year-olds. From the total of 4809 sampled individuals, 4263 were located and identified as eligible for the study. Sampled individuals who were not located were disproportionately older. In comparison to located subjects, subjects who could not be contacted had either moved outside the metropolitan Munich area in the time interval between their registration and the beginning of the study in $1995(8.8 \%)$ or they could not be found with the listed address during the field-work period $(2 \cdot 4 \%)$. From the 4263 individuals a total of 3021 could be assessed at baseline (T0, response rate: $71 \%$ ). Informed consent was obtained from the participants.

The most frequent reasons for non-response at baseline were refusal to participate $(18 \cdot 2 \%)$, followed by a reported lack of time $(3.3 \%)$, failure to contact anyone in the identified household $(3 \cdot 1 \%)$, and failure to contact the sampled individual in the household $(3.0 \%)$. The first follow-up study (T1) was conducted only for subjects aged 14-17 at baseline, whereas the second follow-up study (T2) was conducted for all subjects. In the first follow-up, an average of 20 months (range: 14 to 25 months) after baseline, a total of 1228 interviews were completed (response rate: $88 \%$ ). From the 3021 subjects of the baseline-study, a total of 2548 interviews were completed at the second follow-up, which was conducted an average of 42 (range: 34 to 50 months) months after baseline (response rate: $84 \%$ ). Again, the most frequent reasons for non-response were refusal to participate $(9 \cdot 2 \%)$, failure to contact the subject $(2.7 \%)$ and lack of time $(1.5 \%)$. There was no selective attrition due to age, gender, or geographic distribution between the baseline and second follow-up investigation. More details about the sampling and representativeness of the whole EDSP-sample along with its sociodemographic characteristics have been reported elsewhere (Wittchen et al. 1998 ; Lieb et al. $2000 a, b)$.

\section{Parents}

In the EDSP family supplement, independent diagnostic interviews were conducted with the parents of the younger cohort (those aged 14-17 at baseline). Because we intended to gather detailed information not only about the oc- currence of psychopathology in the respondents' families, but also about natal complications, psychological and somatic symptoms in the respondents' infancy and early childhood, we focused primarily on the respondents' mothers. Fathers were interviewed only if the mother was dead or could not be located. The parents of 1053 adolescents (in 1026 cases the mother, in 27 cases the father) could be interviewed directly, resulting in a response rate of $86 \%$.

\section{Diagnostic assessment}

For the respondents, the diagnostic assessment was based on the computer-assisted version of the Munich-Composite-InternationalDiagnostic-Interview (DIA-X/M-CIDI; Wittchen \& Pfister, 1997), an updated version of the World Health Organization's CIDI version 1.2 (WHO, 1990), supplemented by questions to cover DSM-IV and ICD-10 criteria. At baseline, the M-CIDI lifetime version was used, and at each of the follow-up assessments the M-CIDI interval version was applied.

Reliability and validity of the M-CIDI approach and its alcohol section were tested in several studies. Briefly, test-retest reliability (retest after an average period of 39 days, $N=$ 60 of the community sample) was fair to good for substance use disorders, ranging from kappa $(\kappa)=0.64 \quad$ (Yule's $\mathrm{Y}=0.80$ ) for drug use disorders to $\kappa=0.78$ (Yule's $\mathrm{Y}=0.82$ ) for alcohol use disorders (Lachner et al. 1998; Wittchen et al. 1998c). Procedural clinical validity was examined in 68 patients comparing M-CIDI diagnoses with clinicians' best-estimate diagnoses and taking into account all available information (medical records, diagnostic interview, diagnostic checklist) at the end of the patients' treatment. For substance use disorders the agreement was very good, with $\kappa=0.86$ for any substance use disorder and $\kappa=0.83$ for nicotine dependence (Reed et al. 1998).

\section{Parental history}

In a separate family history module given at baseline and second follow-up, the respondents also provided family history information on all their first degree relatives. Family history items were designed using a modified version of the Family History Research Diagnostic Criteria (Merikangas et al. 1998a,b) as a model. To obtain family history information about DSM- 
IV diagnoses, M-CIDI stem questions were used at baseline to assess the key symptoms. Questions were also asked to determine whether the index subject sought professional help because of the respective symptoms. In the second follow-up, we used an extended version of the family-history module that contained fully structured sections covering DSM-IV criteria for nicotine dependence, major depression, manic episodes, anxiety disorders, alcohol and drug use disorders and bulimic attacks. Respondents provided information about their parents and siblings. Only separation anxiety was assessed for siblings younger than 10 years old. All interviews were administered by highly trained clinical interviewers.

Parents of the younger cohort were assessed independently with the M-CIDI, thus providing direct diagnostic information for the interviewed parent. All interviews were conducted by clinical interviewers who were blind to the diagnostic status of the respective respondents. The parent M-CIDI was supplemented with additional modules that provided: $(a)$ information about respondents' developmental history, and $(b)$ family-history data for the non-interviewed parent and other family members of the respondent (Lachner \& Wittchen, 1997; Lieb et al. $2000 a, b$ ). Family history items in the parent interview were also designed on the basis of the Family History Research Diagnostic Criteria (Merikangas et al. 1998a,b). To obtain family history information about the same DSM-IV Axis I disorders that are in the full M-CIDI, the stem questions from the full M-CIDI were used to assess the key symptoms for the DSM-IV diagnoses. The results reported in this paper are based on the 2427 respondents who completed the entire study period and for whom diagnostic information about psychopathology in both parents was available. A total of $48.5 \%(N=$ $1182)$ of the sample were females, and $51.5 \%$ $(N=1245)$ were males.

\section{Assignment of diagnostic status}

The M-CIDI alcohol section has been described in detail elsewhere (Holly \& Wittchen, 1998; Lachner et al. 1998). Based on the respondents' information given at baseline and follow-up(s), respondents' lifetime alcohol use status was defined according to four categories: (a) 'no/seldom use of alcohol', no lifetime use of alcohol or never use $>11$ glasses of alcohol within a period of 12 months; $(b)$ 'occasional use', use of at least 12 glasses of alcohol within 1 year, but the frequency was never more than twice a week; (c) 'regular use', use of alcohol at least three times a week in the period of peak use, but never 'hazardous' use; and $(d)$ 'hazardous use', an average use of $>40 \mathrm{~g}$ (men) or $20 \mathrm{~g}$ (women) of ethanol per day in the period of peak use. These limits are often used in epidemiological research (Barbor et al. 1987; Saunders et al. 1993). Alcohol use disorders were defined according to DSM-IV criteria. Age of onset of the first abuse or dependence symptom and first age of highest use of alcohol in the period of peak use were also assessed. The outcome measures in this paper are the highest consumption status and alcohol abuse and dependence diagnoses assigned to respondents over all assessment stages. These measures constitute the highest lifetime status of alcohol use and disorders by the time of the second follow-up. For those respondents aged 14-17 at baseline, this lifetime status was assessed from the aggregation of information obtained from baseline (T0) and the first and second follow-up interviews (T1, T2). For respondents aged $>17$ at baseline, the lifetime status was assessed from baseline (T0) and the second follow-up (T2) questions, which refer to the time between baseline and second follow-up.

Family history status was determined by using all available diagnostic information about alcohol abuse or dependence in parents. Therefore, for diagnostic estimates for the parents of the younger cohort, the family history data obtained from the respondent as informant and the MCIDI information of the parent interview were taken into account. For the older cohort, for which no direct parent interviews were available, only family-history information obtained from the respondent was used. The accuracy of family history information was examined by comparing the diagnostic information obtained from the adolescents about their mothers to the information obtained from the mothers themselves, and by comparing the family history information obtained from the respondents about their fathers to the family history information obtained from the mothers about the fathers. For alcohol use disorders, the sensitivity was $53 \%$ for the detection in mothers and $51 \%$ for 
the detection in fathers, and the specificity was $86 \%$ for mothers and $90 \%$ for fathers. The kappa coefficient of agreement between personal interview and family history information reflected a modest level of agreement with a kappa of $0 \cdot 22$. Although kappa values from clinical studies are in general higher, studies in non-clinical samples have found similar results (see Lish et al. 1995; Kendler \& Roy, 1995). The agreement between personal interview and family history information was statistically significant. The lower kappa values obtained in nonclinical samples probably reflect in part the lower base rates of disorders. As the kappa statistics depend on the base rate for a disorder in the population under study (see Spitznagel \& Helzer, 1985, or Grove et al. 1981), we additionally calculated Yule's $\mathrm{Y}$, a statistic that is more independent of prevalence. $Y$ for the agreement of mothers' diagnostic status was 0.54 . For this paper, any indication at the symptomatic level for parental alcohol abuse or dependence was accepted for a positive diagnosis in parents. The diagnostic certainty must therefore be seen on the 'probable' level. For the analyses, parental alcohol abuse and dependence were grouped together under "parental alcohol use disorder (AUD)'. Parental diagnostic estimates were derived by computer.

\section{Statistical analyses}

In the analyses, history of parental AUD was the independent variable and alcohol use and disorders in respondents were the outcomes. For the analyses of overall associations between parental AUD and alcohol use pattern in respondents, cumulative logistic regressions using cumulative odds ratios (CUMOR) were used (Fahrmeier \& Tutz, 1994). To assess associations with the different progression steps of alcohol use, continuation logistic regressions (Greenland, 1995) with continuation odds ratios (COR) were applied. The sequence of analyses is: (1) association with being at least occasional user $v$. being no/seldom user ("progression into occasional use'); (2) association with being at least regular user $v$. being occasional user ('progression into regular use'); (3) association with being hazardous user $v$. being regular user ('progression into hazardous use'). The corresponding CORs do not serve for quantitative comparisons but rather to assess whether a covariate is related with different progression steps, as one would assume a decreasing sequence of CORs under the cumulative model if CUMOR $>1$. Therefore, adjusted CORs $\left(\mathrm{COR}^{\text {adj }}\right)$ were computed by dividing observed CORs by the CORs expected under the cumulative model (MacLean, 1988). A bootstrapprocedure was applied to calculate $95 \%$ confidence intervals for these adjusted CORs (Efron \& Tibshirani, 1993).

Associations between parental AUD and alcohol use disorders in respondents were analysed by using logistic regressions for binary responses. Age of onset characteristics were examined with the Kaplan-Meier method (Andersen \& Keiding, 1996). Overall differences in terms of hazard rates (HR) were tested with the stratified Cox-model for discrete time (with age-year-cohorts being the stratas to adjust for cohort effects). The interaction terms parental AUD*age were added to the model when the proportional hazards assumption was violated. The latter was tested with so-called Schoenfeldresiduals (Grambsch \& Therneau, 1994). An interaction parental AUD*age with HR $<1$ indicates that probands with affected parents have an earlier onset, e.g. of alcohol abuse, dependent on the fact that they report the outcome under consideration.

Analyses were performed using the Stata software package (StataCorp, 1999) and applying the Huber-White sandwich matrix for weighted data (Royall, 1986). Sex and age of respondent were controlled for by including them as independent variables in the respective model. This procedure was done because both variables might be related to the outcomes in the offspring as well as to the report of AUD in parents. All associations were tested for interaction with gender of the respondent, and in cases of a significant interaction, associations were then determined for male and female offspring. To protect for misleading results obtained by aggregating the two cohorts with different ascertainment strategies, all associations were tested for an interaction effect with age cohort. In case of significance, analyses were run separately within each cohort.

Due to the different sampling probabilities (for different age groups), relative weights inversely proportional to the sampling fraction were used. In addition, these weights also 
accounted for non-response according to age, gender and geographic distribution (urban $v$. rural) of the respondents (Wittchen et al. 1998b).

\section{RESULTS}

Alcohol use disorders in parents and alcohol use and disorders in respondents

Study criteria for lifetime alcohol abuse or dependence were fulfilled by $7.5 \%$ of mothers

Table 1. Alcohol use disorders in parents and alcohol use patterns and disorders in offspring

\begin{tabular}{|c|c|c|c|c|}
\hline & \multicolumn{4}{|c|}{ Frequency $\dagger$} \\
\hline & $N$ & $\mathrm{NW}$ & $\% \mathrm{~W}$ & $(95 \% \mathrm{CI}) \%$ \\
\hline \multicolumn{5}{|c|}{ Alcohol use disorders in parents } \\
\hline Neither parent & 1818 & 1866 & $77 \cdot 5$ & $(75 \cdot 5-79 \cdot 3)$ \\
\hline Mother & 221 & 181 & $7 \cdot 5$ & $(6 \cdot 5-8 \cdot 7)$ \\
\hline Father & 477 & 436 & $18 \cdot 1$ & $(16 \cdot 5-19 \cdot 9)$ \\
\hline Mother only & 132 & 107 & $4 \cdot 4$ & $(3 \cdot 6-5 \cdot 4)$ \\
\hline Father only & 388 & 362 & $15 \cdot 0$ & $(13 \cdot 5-16 \cdot 7)$ \\
\hline Either parent & 609 & 543 & $22 \cdot 5$ & $(20 \cdot 8-24 \cdot 4)$ \\
\hline One parent & 520 & 469 & $19 \cdot 5$ & $(17 \cdot 7-21 \cdot 3)$ \\
\hline Both parents & 89 & 74 & $3 \cdot 1$ & $(2 \cdot 4-3 \cdot 9)$ \\
\hline \multicolumn{5}{|c|}{ Alcohol outcomes in respondents } \\
\hline \multicolumn{5}{|c|}{ Alcohol use } \\
\hline \multicolumn{5}{|c|}{ No/seldom use } \\
\hline Males & 119 & 86 & $7 \cdot 2$ & $(5 \cdot 9-8 \cdot 8)$ \\
\hline Females & 204 & 185 & $15 \cdot 3 *$ & $(13 \cdot 2-17 \cdot 7)$ \\
\hline Total & 323 & 271 & $11 \cdot 2$ & $(9 \cdot 9-12 \cdot 6)$ \\
\hline \multicolumn{5}{|c|}{ Occasional use } \\
\hline Males & 718 & 643 & $53 \cdot 5$ & $(50 \cdot 3-56 \cdot 6)$ \\
\hline Females & 804 & 818 & $67 \cdot 8 *$ & $(64 \cdot 7-70 \cdot 8)$ \\
\hline Total & 1522 & 1461 & $61 \cdot 1$ & $(58 \cdot 9-63 \cdot 3)$ \\
\hline \multicolumn{5}{|l|}{ Regular use } \\
\hline Males & 218 & 251 & $20 \cdot 9 *$ & $(18 \cdot 3-23 \cdot 7)$ \\
\hline Females & 61 & 76 & $6 \cdot 3$ & $(4 \cdot 8-8 \cdot 3)$ \\
\hline Total & 279 & 328 & $13 \cdot 6$ & $(12 \cdot 0-15 \cdot 3)$ \\
\hline \multicolumn{5}{|c|}{ Hazardous use } \\
\hline Males & 190 & 222 & $18 \cdot 5^{*}$ & $(16 \cdot 0-21 \cdot 2)$ \\
\hline Females & 113 & 127 & $10 \cdot 5$ & $(8 \cdot 6-12 \cdot 8)$ \\
\hline Total & 303 & 349 & $14 \cdot 5$ & $(12 \cdot 9-16 \cdot 3)$ \\
\hline \multicolumn{5}{|c|}{ Alcohol use disorders } \\
\hline \multicolumn{5}{|c|}{ Alcohol abuse w/o dependence } \\
\hline Males & 353 & 337 & $28 \cdot 0^{*}$ & $(25 \cdot 2-30 \cdot 9)$ \\
\hline Females & 131 & 140 & $11 \cdot 6$ & $(9 \cdot 6-13 \cdot 9)$ \\
\hline Total & 484 & 477 & $19 \cdot 8$ & $(18 \cdot 1-21 \cdot 6)$ \\
\hline \multicolumn{5}{|c|}{ Alcohol dependence } \\
\hline Males & 158 & 173 & $14 \cdot 4 *$ & $(12 \cdot 2-16 \cdot 9)$ \\
\hline Females & 44 & 44 & $3 \cdot 7$ & $(2 \cdot 6-5 \cdot 1)$ \\
\hline Total & 202 & 217 & $9 \cdot 0$ & $(7 \cdot 8-10 \cdot 4)$ \\
\hline
\end{tabular}

$\dagger N$, unweighted number; $N \mathrm{w}$, weighted number; $\% \mathrm{w}$, weighted percentage. Unweighted $N$ total $=2427$; weighted $N$ total $=2409$. \$ The $95 \%$ confidence intervals refers to the weighted percentages. $\S$ No/seldom use, no lifetime consumption or never use at least 12 times/year; occasional use, use of at least 12 times/year, frequency was never more than twice a week; regular use, in the period of peak use, at least three times a week, no hazardous use; and hazardous use, in the period of peak use, an average of $>20 \mathrm{~g} /$ day in females and $>40 \mathrm{~g} /$ day in males.

* Significant gender difference at the 0.05 level. and $18.1 \%$ of fathers (Table 1 ). In $19.5 \%$ and $3.1 \%$ of the sample, respectively, one or both parents were affected. At the second follow-up, $11.2 \%$ of the respondents reported no or seldom use of alcohol. Criteria for lifetime 'occasional use' were met by $61 \cdot 1 \%$ of respondents, $13.6 \%$ fulfilled lifetime 'regular use' criteria, and $14.5 \%$ reported lifetime 'hazardous use'. Regarding DSM-IV alcohol use disorders, $19 \cdot 8 \%$ fulfilled criteria for alcohol abuse, while $9 \cdot 0 \%$ fulfilled criteria for alcohol dependence. Across all categories, males reported higher rates of the outcome than females. Rates of affected parents were similar for males and females: $7 \cdot 1 \%$ of the males and $8.0 \%$ of the females (design-based $F(1,2426)=0.67 ; \quad P=0.41)$ had an affected mother and $17 \cdot 6 \%$ of the males and $18.6 \%$ of the females (design-based $F(1,2426)=0.34$; $P=0.56)$ had an affected father.

\section{Progression patterns in offspring}

The overall associations between parental AUD and the four levels of offsprings' alcohol use were first examined using cumulative logistic regressions (Table 2).

AUD in both mother (CUMOR $=1 \cdot 65 ; 95 \%$ $\mathrm{CI}=1 \cdot 17-2 \cdot 32)$ and father $(\mathrm{CUMOR}=1 \cdot 35$; $95 \% \mathrm{CI}=1.05-1.73)$ were associated with an increased risk to shift towards higher use categories among offspring. Specifically, offspring whose parents were both affected had a significantly increased risk of shift into higher use categories than offspring with no affected parents $(\mathrm{CUMOR}=2 \cdot 88 ; 95 \% \mathrm{CI}=1 \cdot 83-4 \cdot 53)$ or with one affected parent (CUMOR $=2 \cdot 48$; $95 \% \mathrm{CI}=1 \cdot 52-4 \cdot 06)$. No differences in associations were found for gender and cohort. The examination of the effect of parental AUD on different progression steps into higher use levels revealed that maternal AUD was associated with progression from occasional into regular use, whereas paternal AUD was additionally associated with progression from regular into hazardous use (Table 3).

Paternal AUD in particular was associated with progression from regular into hazardous use $\left(\mathrm{COR}^{\mathrm{adj}}=1 \cdot 58 ; 95 \% \mathrm{CI}=1 \cdot 00-2 \cdot 68\right)$. Comparisons across mating types revealed that only offspring with two affected parents had an increased risk for progression from occasional into regular use. With the exception of female offspring of affected mothers only revealing a 
Table 2. Offspring alcohol use status (weighted \%) by parental alcohol use disorders

\begin{tabular}{|c|c|c|c|c|c|c|c|c|c|c|c|c|c|c|}
\hline \multirow{4}{*}{ Parental history } & \multicolumn{14}{|c|}{ Respondents' alcohol consumption status (peak lifetime episode $\mathrm{T} 0 / \mathrm{T} 1 / \mathrm{T} 2$ ) } \\
\hline & \multicolumn{3}{|c|}{ No/seldom use } & \multicolumn{3}{|c|}{ Occasional use } & \multicolumn{3}{|c|}{ Regular use } & \multicolumn{3}{|c|}{ Hazardous use } & \multirow{2}{*}{\multicolumn{2}{|c|}{ Overall association: }} \\
\hline & \multirow{2}{*}{$\begin{array}{c}\mathrm{M} \dagger \\
(N \mathrm{w}=86) \\
\% \mathrm{w}\end{array}$} & \multirow{2}{*}{$\begin{array}{c}\mathrm{F} \dagger \\
\left(N_{\mathrm{w}}=185\right) \\
\% \mathrm{w}\end{array}$} & \multirow{2}{*}{$\begin{array}{c}\text { Total } \\
(N \mathrm{w}=271) \\
\% \mathrm{w}\end{array}$} & \multirow{2}{*}{$\begin{array}{c}\mathrm{M} \dagger \\
(N \mathrm{w}=643) \\
\% \mathrm{w}\end{array}$} & \multirow{2}{*}{$\begin{array}{c}\mathrm{F} \dot{\dagger} \\
(N \mathrm{w}=818) \\
\% \mathrm{w}\end{array}$} & \multirow{2}{*}{$\begin{array}{c}\text { Total } \\
(N \mathrm{w}=1461) \\
\% \mathrm{w}\end{array}$} & \multirow{2}{*}{$\begin{array}{c}\mathrm{M} \dagger \\
(N \mathrm{w}=251) \\
\% \mathrm{w}\end{array}$} & \multirow{2}{*}{$\begin{array}{c}\mathrm{F} \dagger \\
(N \mathrm{w}=76) \\
\% \mathrm{w}\end{array}$} & \multirow{2}{*}{$\begin{array}{c}\text { Total } \\
(N \mathrm{w}=328) \\
\% \mathrm{w}\end{array}$} & \multirow{2}{*}{$\begin{array}{c}\mathrm{M} \dagger \\
(N \mathrm{w}=222) \\
\% \mathrm{w}\end{array}$} & \multirow{2}{*}{$\begin{array}{c}\mathrm{F}^{\dagger} \\
(N \mathrm{w}=127) \\
\% \mathrm{w}\end{array}$} & \multirow{2}{*}{$\begin{array}{c}\text { Total } \\
(N \mathrm{w}=349) \\
\% \mathrm{w}\end{array}$} & & \\
\hline & & & & & & & & & & & & & CUMOR & $(95 \% \mathrm{Cl})$ \\
\hline \multirow{2}{*}{\multicolumn{15}{|c|}{ Gender of affected parent }} \\
\hline & \multicolumn{14}{|c|}{ Mother } \\
\hline No & 6.9 & $15 \cdot 7$ & $11 \cdot 3$ & $53 \cdot 7$ & 68.2 & $60 \cdot 9$ & $21 \cdot 1$ & $6 \cdot 2$ & $13 \cdot 7$ & $18 \cdot 3$ & $10 \cdot 0$ & $14 \cdot 2$ & - & \\
\hline \multirow{2}{*}{\multicolumn{15}{|c|}{ Father }} \\
\hline & & & & & & & & & & & & & & \\
\hline & $7 \cdot 0$ & $15 \cdot 4$ & $11 \cdot 2$ & $53 \cdot 7$ & $68 \cdot 7$ & $61 \cdot 7$ & $22 \cdot 1$ & $6 \cdot 2$ & $14 \cdot 2$ & $17 \cdot 2$ & $9 \cdot 8$ & $13 \cdot 5$ & - & \\
\hline Yes & 8.0 & $15 \cdot 0$ & $11 \cdot 6$ & $52 \cdot 3$ & $64 \cdot 3$ & 58.7 & 15.5 & 6.9 & $11 \cdot 1$ & $24 \cdot 1$ & $14 \cdot 0$ & 18.9 & $1 \cdot 35^{*}$ & $(1 \cdot 05-1 \cdot 73$ \\
\hline \multicolumn{15}{|l|}{ Parental disorder } \\
\hline $\begin{array}{l}\text { Neither mother } \\
\text { nor father }\end{array}$ & 6.5 & $15 \cdot 6$ & $11 \cdot 0$ & $53 \cdot 5$ & $68 \cdot 8$ & $61 \cdot 0$ & $22 \cdot 2$ & $6 \cdot 4$ & $14 \cdot 4$ & $17 \cdot 8$ & $9 \cdot 2$ & $13 \cdot 6$ & - & \\
\hline Mother only & $16 \cdot 2$ & $11 \cdot 6$ & $13 \cdot 5$ & 58.0 & $67 \cdot 0$ & $63 \cdot 2$ & $20 \cdot 1$ & $3 \cdot 4$ & $10 \cdot 4$ & 5.8 & $18 \cdot 1$ & $12 \cdot 9$ & $1 \cdot 15$ & $(0 \cdot 74-1 \cdot 78$ \\
\hline Father only & 8.8 & $15 \cdot 8$ & $12 \cdot 5$ & $54 \cdot 9$ & $65 \cdot 3$ & $60 \cdot 3$ & $15 \cdot 6$ & $5 \cdot 2$ & $10 \cdot 1$ & $20 \cdot 7$ & $13 \cdot 8$ & $17 \cdot 1$ & $1 \cdot 16$ & $(0 \cdot 88-1 \cdot 53$ \\
\hline One parent§ & $10 \cdot 3$ & $14 \cdot 8$ & $12 \cdot 7$ & 55.5 & $65 \cdot 7$ & $61 \cdot 0$ & $16 \cdot 7$ & $4 \cdot 7$ & $10 \cdot 2$ & 17.6 & $14 \cdot 8$ & $16 \cdot 1$ & $1 \cdot 16$ & $(0 \cdot 90-1 \cdot 48$ \\
\hline & $4 \cdot 9$ & $10 \cdot 5$ & 7.5 & $41 \cdot 4$ & $58 \cdot 8$ & $49 \cdot 5$ & $14 \cdot 9$ & $16 \cdot 1$ & $15 \cdot 4$ & 38.9 & $14 \cdot 5$ & 27.5 & $2 \cdot 88^{*}$ & $(1 \cdot 83-4.53$ \\
\hline $\begin{array}{l}\text { Both } v \text {. one parent } \\
\text { affected }\end{array}$ & & & & & & & & & & & & & $2 \cdot 48^{*}$ & $(1 \cdot 52-4 \cdot 06$ \\
\hline
\end{tabular}

$N \mathrm{w}$, weighted numbers; \%w, weighted percentages. Since the $N \mathrm{w}$ and $\% \mathrm{w}$ values have been rounded, the sum of the individual $N \mathrm{ws}$ and $\%$ ws does not always exactly equal $100 \%$. $\dagger$ Sex of offspring: M, male offspring; F, female offspring.

\$ Cumulative logistic regression, CUMOR indicates cumulative odds ratio; adjusted for age and gender effects.

No significant interactions between parental alcoholism and gender in offspring were found at the 0.05 level.

No significant interactions between parental alcoholism and age cohort were found at the 0.05 level.

$\S$ Reference group are respondents with neither affected mother nor father.

$* P<0 \cdot 05$. 
Table 3. Association between alcohol use disorders in parents and progression into alcohol consumption in offspring

\begin{tabular}{|c|c|c|c|c|c|c|c|c|c|c|c|c|}
\hline \multirow[b]{3}{*}{ Parental history } & \multicolumn{6}{|c|}{$\begin{array}{l}\text { Offsprings' alcohol consumption status } \\
\text { (peak lifetime episode } \mathrm{T} 0 / \mathrm{T} 1 / \mathrm{T} 2 \text { ) }\end{array}$} & & & & & & \\
\hline & \multicolumn{2}{|c|}{$\begin{array}{c}\text { At least } \\
\text { occasional use } \\
(N \mathrm{~W}=2138)\end{array}$} & \multicolumn{2}{|c|}{$\begin{array}{l}\text { At least regular use } \\
\text { among occasional users } \\
(N \mathrm{~W}=677)\end{array}$} & \multicolumn{2}{|c|}{$\begin{array}{l}\text { Hazardous use } \\
\text { among regular users } \\
(N \mathrm{w}=349)\end{array}$} & \multicolumn{2}{|c|}{$\begin{array}{l}\text { Progression into } \\
\text { occasional use }\end{array}$} & \multicolumn{2}{|c|}{$\begin{array}{l}\text { Progression into } \\
\text { regular use }\end{array}$} & \multicolumn{2}{|c|}{$\begin{array}{l}\text { Progression into } \\
\text { hazardous use }\end{array}$} \\
\hline & $N \mathrm{~W}$ & $\% \mathrm{w}$ & $N \mathrm{~W}$ & $\% \mathrm{w}$ & $N \mathrm{w}$ & $\% \mathrm{w}$ & $\mathrm{COR}_{\dagger}+$ & $(95 \% \mathrm{CI})$ & $\mathrm{COR}$ & $(95 \% \mathrm{CI})$ & $\mathrm{COR}$ & $(95 \% \mathrm{CI})$ \\
\hline \multicolumn{13}{|l|}{ Gender of affected parent } \\
\hline \multicolumn{13}{|l|}{ Mother } \\
\hline No $(N \mathrm{~W}=2228)$ & 1977 & $88 \cdot 8$ & 620 & $31 \cdot 4$ & 315 & $50 \cdot 8$ & - & & - & & - & \\
\hline Yes $(N \mathrm{w}=181)$ & 161 & $88 \cdot 9$ & 57 & $35 \cdot 3$ & 34 & $60 \cdot 2$ & $1 \cdot 36$ & $(0 \cdot 86-2 \cdot 14)$ & $1 \cdot 76^{*}$ & $(1 \cdot 16-2 \cdot 65)$ & $1 \cdot 33$ & $(0 \cdot 71-2 \cdot 50)$ \\
\hline \multicolumn{13}{|c|}{ 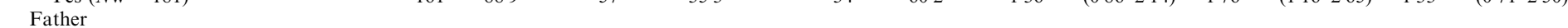 } \\
\hline No $(N \mathrm{w}=1972)$ & 1753 & 88.9 & 547 & $31 \cdot 2$ & 267 & $48 \cdot 9$ & - & & - & & - & \\
\hline Yes $(N \mathrm{~W}=436)$ & 386 & $88 \cdot 4$ & 131 & $33 \cdot 9$ & 82 & $63 \cdot 0$ & 1.09 & $(0 \cdot 76-1 \cdot 56)$ & $1 \cdot 40^{*}$ & $(1 \cdot 05-1 \cdot 88)$ & $1.72 *$ & $(1 \cdot 06-2 \cdot 78)$ \\
\hline \multicolumn{13}{|l|}{ Parental disorder } \\
\hline Neither mother nor father $(N \mathrm{~W}=1866)$ & 1660 & $89 \cdot 0$ & 522 & $31 \cdot 4$ & 253 & $48 \cdot 6$ & - & & - & & - & \\
\hline Mother only $\$(N \mathrm{w}=107)$ & 92 & $86 \cdot 5$ & 25 & $26 \cdot 9$ & 14 & $55 \cdot 2$ & $1 \cdot 10$ & $(0 \cdot 62-1 \cdot 93)$ & 1.21 & $(0 \cdot 67-2 \cdot 21)$ & $1 \cdot 12$ & $(0 \cdot 48-2 \cdot 60)$ \\
\hline Father only $(N \mathrm{w}=362)$ & 317 & $87 \cdot 6$ & 99 & $31 \cdot 1$ & 62 & 62.7 & 0.99 & $(0.67-1 \cdot 46)$ & 1.20 & $(0 \cdot 87-1 \cdot 68)$ & 1.69 & $(0 \cdot 99-2 \cdot 90)$ \\
\hline One parent: $(N \mathrm{~W}=469)$ & 409 & $87 \cdot 3$ & 123 & $30 \cdot 3$ & 76 & $61 \cdot 2$ & $1 \cdot 02$ & $(0.72-1.43)$ & 1.21 & $(0.89-1.63)$ & 1.56 & $(0.96-2.51)$ \\
\hline Both parents $(N \mathrm{~W}=74)$ & 69 & $92 \cdot 5$ & 32 & $46 \cdot 5$ & 20 & $64 \cdot 1$ & $2 \cdot 00$ & $(0 \cdot 94-4 \cdot 26)$ & $2 \cdot 93^{*}$ & $(1 \cdot 74-4.94)$ & 1.83 & $(0.74-4.50)$ \\
\hline Both $v$. one parent affected & & & & & & & 1.96 & $(0 \cdot 89-4 \cdot 34)$ & $2 \cdot 42 *$ & $(1 \cdot 37-4 \cdot 26)$ & $1 \cdot 17$ & $(0.44-3.06)$ \\
\hline
\end{tabular}

$N \mathrm{w}$, weighted number; \% w weighted percentages.

pentrolled for age and gender of the respondent.

$\$$ Reference group are respondents with neither affected mother nor father.

Significant interaction effect was found for gender of offspring as follows: interaction gender* only mother affected OR for progression into hazardous use $=10 \cdot 55(95 \% \mathrm{CI}=1 \cdot 46-76 \cdot 11)$; COR

for male offspring $=0.36(95 \% \mathrm{CI}=0.07-1 \cdot 69)$; COR for female offspring $=3.66(95 \% \mathrm{CI}=0.92-14 \cdot 56)$

* $P<0 \cdot 05$ 


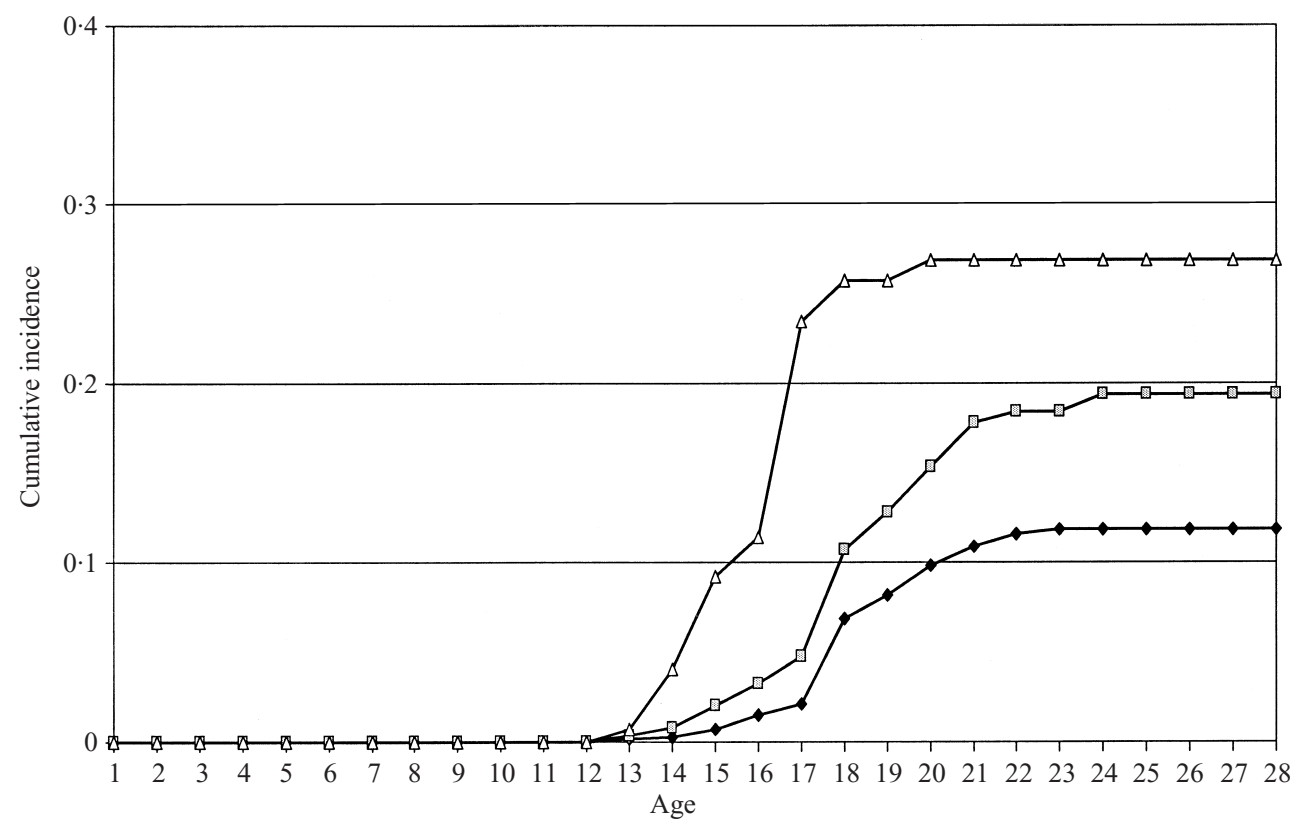

Fig. 1. Age of onset of hazardous use of alcohol by parental history of alcohol use disorders. ( $\bullet$, Neither parent affected $(N \mathrm{w}=1866) ;$ 圆, one parent affected $(N \mathrm{~W}=469) ; \triangle$, both parents affected $(N \mathrm{~W}=74)$.

higher risk for progression from occasional into hazardous use of alcohol, no notable differences in risks were found between male and female offspring. Also, no differences in associations were found between the younger and older cohort.

\section{Age of first onset of hazardous alcohol use in offspring}

Fig. 1 shows the age-specific cumulative probability of reporting hazardous use of alcohol in offspring by number of affected parents. In all three groups the rates increase after age 13, but the increase is steeper in respondents with affected parents. The peak incidence period of respondents with two affected parents is between the ages of 14 and 17; then the rates plateau after age 18. By this age, $>25 \%$ of these respondents reported hazardous use of alcohol. For the other two groups, the rates increase at a lower level until age 24, with higher rates in respondents with one affected parent. Overall hazard rates for respondents with one affected parent $(\mathrm{HR}=1.42 ; 95 \% \mathrm{CI}=1.06-1.90)$ and two affected parents $(\mathrm{HR}=3.44 ; 95 \% \mathrm{CI}=$ 1.99-5.93) were significantly different from those of respondents without affected parents. Hazard rates for respondents with two affected parents were also higher than those for respondents with one affected parent $(\mathrm{HR}=2.42 ; 95 \% \mathrm{CI}=$ 1.36-4.32). Hazardous use had an earlier onset in respondents with two affected parents when compared to respondents without affected parents (HR for interaction with age $=0.62$; $95 \% \mathrm{CI}=0.50-0.77)$, but there was no such finding when only one parent was affected (HR for interaction with age $=0.96 ; 95 \% \mathrm{CI}=$ $0 \cdot 80-1 \cdot 16)$. No significant interactions between gender and cohort of the respondent and parental alcoholism were found.

\section{Alcohol abuse and dependence in offspring}

Respondents with an affected father had significantly higher rates of alcohol abuse and dependence than respondents without an affected father (Table 4). No differences were found in respondents with or without affected mothers. However, subsetting the analyses to subjects with only affected mother and only affected father did not find significant differences between maternal and paternal associations (alcohol abuse: OR father only $v$. mother only $=1 \cdot 3$; $95 \% \mathrm{CI}=0 \cdot 7-2 \cdot 4$; alcohol dependence: OR father only $v$. mother only $=1 \cdot 5 ; 95 \% \mathrm{CI}=$ 
Table 4. Associations between alcohol use disorders in parent and offspring

\begin{tabular}{|c|c|c|c|c|c|c|c|c|c|c|c|c|c|}
\hline \multirow[b]{3}{*}{ Parental history } & \multicolumn{9}{|c|}{ Offsprings' diagnostic status (cum. lifetime prevalence $\mathrm{T} 0 / \mathrm{T} 1 / \mathrm{T} 2) \dagger$} & \multirow{2}{*}{\multicolumn{2}{|c|}{$\begin{array}{l}\text { Association with } \\
\text { alcohol abuse: }\end{array}$}} & \multirow{2}{*}{\multicolumn{2}{|c|}{$\begin{array}{l}\text { Association with } \\
\text { alcohol dependence }\end{array}$}} \\
\hline & \multicolumn{3}{|c|}{ No $\mathrm{DX}(\mathrm{NW}=1715)$} & \multicolumn{3}{|c|}{ Abuse $(N \mathrm{~W}=477)$} & \multicolumn{3}{|c|}{ Dependence $(N \mathrm{w}=217)$} & & & & \\
\hline & $N \mathrm{~W}$ & $\% \mathrm{w}$ & $(95 \% \mathrm{CI})$ & $N \mathrm{w}$ & $\% \mathrm{w}$ & $(95 \% \mathrm{CI})$ & $N \mathrm{w}$ & $\% \mathrm{w}$ & $(95 \% \mathrm{CI})$ & OR§ & $(95 \% \mathrm{CI})$ & OR§ & $(95 \% \mathrm{CI})$ \\
\hline \multicolumn{14}{|l|}{ Gender of affected parent } \\
\hline \multirow{2}{*}{\multicolumn{14}{|c|}{ Mother }} \\
\hline No $(N \mathrm{w}=2228)$ & 1594 & $71 \cdot 6$ & & & $19 \cdot 7$ & $(17 \cdot 8-21 \cdot 7)$ & 195 & $8 \cdot 8$ & $(7 \cdot 4-10 \cdot 3)$ & & & - & \\
\hline Yes $(N \mathrm{w}=181)$ & 121 & $67 \cdot 0$ & $(59 \cdot 7-73 \cdot 5)$ & 38 & $21 \cdot 0$ & $(15 \cdot 8-27 \cdot 3)$ & 22 & $12 \cdot 1$ & $(7 \cdot 8-18 \cdot 2)$ & 1.29 & $(0 \cdot 85-1 \cdot 95)$ & $1 \cdot 68$ & $(0 \cdot 97-2 \cdot 89)$ \\
\hline \multicolumn{14}{|l|}{ Father } \\
\hline No $(N \mathrm{w}=1972)$ & 1445 & $73 \cdot 3$ & $(70 \cdot 9-75 \cdot 5)$ & 374 & $19 \cdot 0$ & $(17 \cdot 1-21 \cdot 1)$ & 153 & 7.8 & $(6 \cdot 5-9 \cdot 3)$ & - & & - & \\
\hline Yes $(N \mathrm{w}=436)$ & 270 & $61 \cdot 9$ & $(56 \cdot 9-66 \cdot 7)$ & 102 & $23 \cdot 4$ & $(19 \cdot 5-27 \cdot 8)$ & 64 & $14 \cdot 6$ & $(11 \cdot 2-18 \cdot 8)$ & $1.66^{*}$ & $(1 \cdot 25-2 \cdot 20)$ & $2 \cdot 31^{*}$ & $(1 \cdot 60-3 \cdot 34)$ \\
\hline \multicolumn{14}{|l|}{ Parental disorder } \\
\hline Neither mother nor father $(N \mathrm{w}=1866)$ & 1367 & $73 \cdot 3$ & $(70 \cdot 9-75 \cdot 6)$ & 355 & $19 \cdot 0$ & $(17 \cdot 0-21 \cdot 2)$ & 144 & $7 \cdot 7$ & $(6 \cdot 3-9 \cdot 3)$ & - & & - & \\
\hline Mother only $\uparrow(N \mathrm{~W}=107)$ & 78 & $72 \cdot 7$ & $(63 \cdot 4-80 \cdot 5)$ & 20 & $18 \cdot 3$ & $(12 \cdot 2-26 \cdot 4)$ & 10 & $9 \cdot 0$ & $(4 \cdot 5-17 \cdot 1)$ & 1.08 & $(0 \cdot 63-1 \cdot 83)$ & 1.53 & $(0 \cdot 67-3 \cdot 48)$ \\
\hline Father only $(N \mathrm{w}=362)$ & 226 & $62 \cdot 6$ & $(57 \cdot 0-67 \cdot 9)$ & 84 & $23 \cdot 1$ & $(18 \cdot 8-28 \cdot 1)$ & 52 & $14 \cdot 3$ & $(10 \cdot 6-18 \cdot 9)$ & $1.37^{*}$ & $(1 \cdot 01-1 \cdot 85)$ & $2 \cdot 30^{*}$ & $(1.54-3.45)$ \\
\hline One parent $\tau^{-}(N \mathrm{~W}=469)$ & 304 & $64 \cdot 9$ & $(60 \cdot 1-69 \cdot 5)$ & 103 & $22 \cdot 0$ & $(18 \cdot 3-26 \cdot 2)$ & 61 & $13 \cdot 1$ & $(9 \cdot 9-17 \cdot 7)$ & $1 \cdot 50^{*}$ & $(1 \cdot 13-2 \cdot 00)$ & $2 \cdot 14^{*}$ & $(1 \cdot 46-3 \cdot 14)$ \\
\hline Both parents $(N \mathrm{w}=74)$ & 44 & $58 \cdot 7$ & $(47 \cdot 2-69 \cdot 3)$ & 19 & $24 \cdot 9$ & $(16 \cdot 7-35 \cdot 4)$ & 12 & $16 \cdot 4$ & $(9 \cdot 3-27 \cdot 2)$ & 1.93* & $(1.08-3.44)$ & $2 \cdot 75^{*}$ & $(1 \cdot 42-5 \cdot 31)$ \\
\hline Both $v$. one parent affected & & & & & & & & & & 1.28 & $(0 \cdot 70-2 \cdot 35)$ & 1.28 & $(0.64-2.55)$ \\
\hline
\end{tabular}

$N \mathrm{w}$, weighted number; \%w weighted percentages. OR indicates odds ratio.

$\dagger$ Alcohol abuse and dependence as defined by the DSM-IV; abuse excludes dependence. All associations are controlled for age and gender of the respondent.

\$ Reference group are respondents without any alcohol disorder/dependence.

$\S$ OR indicates odds ratio; all odds ratios are adjusted for age and gender of respondent.

- Reference group are respondents with neither affected mother nor father.

* $P<0.05$. 

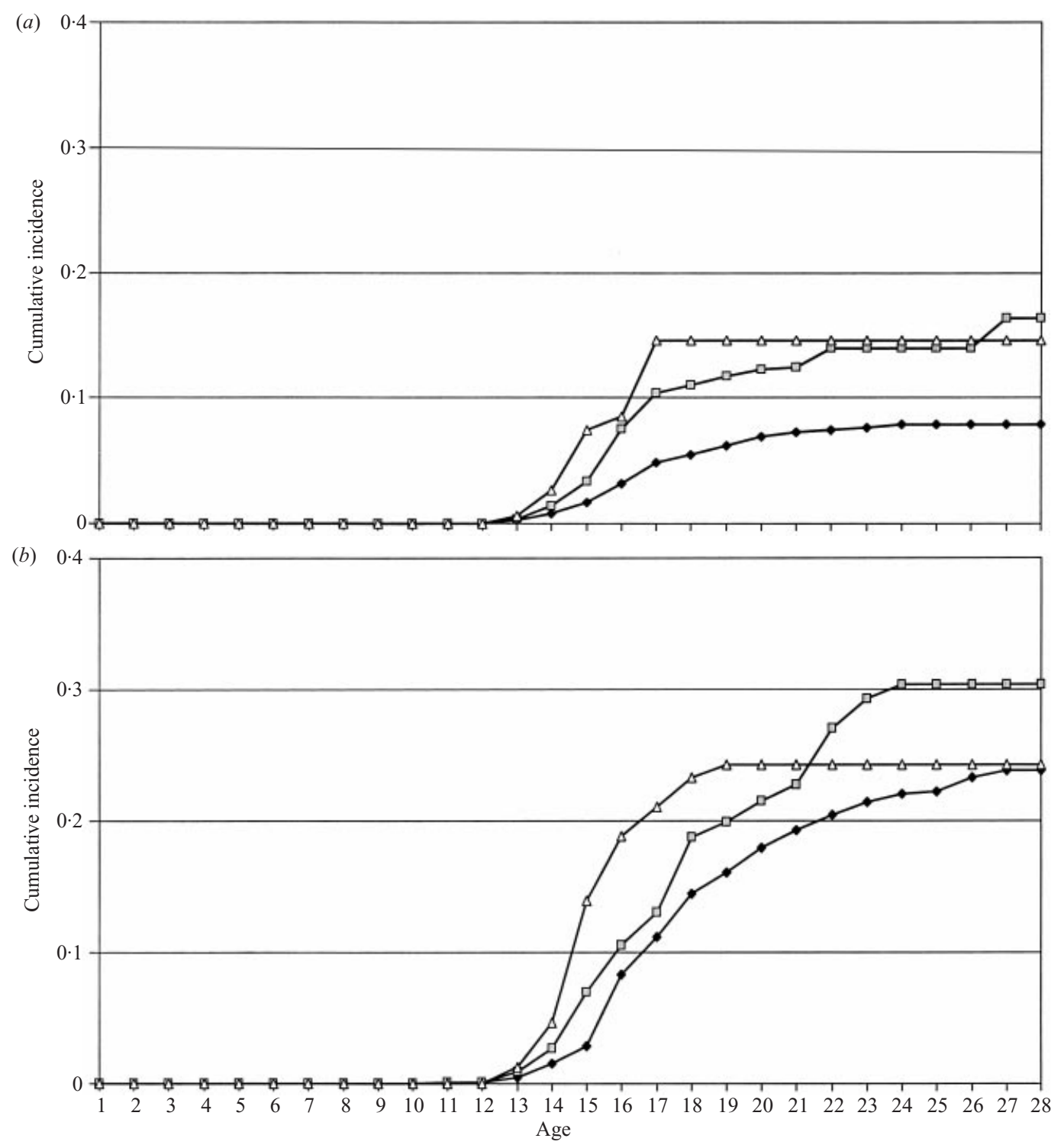

Fig. 2. (a) Age of onset of alcohol dependence by parental loading of alcohol use disorder. (b) Age of onset of alcohol abuse by parental loading of alcohol use disorder. $(\bullet$, Neither parent affected $(N \mathrm{w}=1866)$; $⿴$, one parent affected $(N \mathrm{w}=469)$; $\triangle$, both parents affected $(N \mathrm{~W}=74)$.)

0.6-3·5). Respondents with one or two affected parents had elevated rates of alcohol abuse and dependence. There were no differences across the mating types. Logistic regressions revealed higher associations for alcohol dependence than for abuse. No differences in associations were found for gender and cohort.
First onset of abuse and dependence in offspring

Fig. 2 shows the offsprings' age-specific cumulative incidence rates for DSM-IV alcohol abuse and dependence by number of affected parents. Focusing on dependence, the rates increase around age 13. The steepest increase was found 
at age 14 in respondents with two affected parents, and the rates remained stable at a high level $(15 \%)$ at age 17 . Rates in respondents without affected parents increased only slightly until age 24 . Statistical analyses showed that the hazard rates of respondents with one $(\mathrm{HR}=$ $2.06 ; 95 \% \mathrm{CI}=1.45-2.91)$ and two affected parents $(\mathrm{HR}=2.83 ; 95 \% \mathrm{CI}=1.53-5.29)$ were higher than those of respondents without affected parents. No differences were found between respondents with one or two affected parents. The interaction age*both parents affected barely failed to reach significance (HR $=0.75 ; 95 \% \mathrm{CI}=0.55-1.01 ; P=0.058)$.

The findings are somewhat different for alcohol abuse. As for alcohol dependence, the rates of alcohol abuse in all three groups began to increase at age 13 , but no differences were found between the different curves. However, a significant interaction age* both parents affected $(\mathrm{HR}=0.66 ; 95 \% \quad \mathrm{CI}=0.54-0.81) \quad$ indicates an earlier onset of alcohol abuse in these respondents when compared to respondents without affected parents. There was no such effect for the interaction age*one parent affected $(\mathrm{HR}=0.97 ; 95 \% \mathrm{CI}=0 \cdot 87-1 \cdot 08)$. For both dependence and abuse, no differences in associations were found for gender and cohort.

\section{DISCUSSION}

The key finding that children of parents with AUD are more likely to develop alcohol use and alcohol use disorders is by and large consistent with previous findings. The findings of this study, however, extend existing knowledge insofar as: (1) parent-offspring associations were explored using DSM-IV criteria in a representative community sample, unaffected by potential clinical selection bias; (2) the data on offspring respondents were collected prospectively, so outcomes should be less biased and more valid and reliable; (3) subjects were examined across the period of risk of initial onset of alcohol use and during peak phase of transition to regular use; (4) associations between parental alcoholism and specific progression patterns of alcohol use in offspring were evaluated, as were (5) the effects of parental AUDs on patterns of age of first onset of alcohol use and disorders in offspring.
Consistent with numerous previous studies (Sher et al. 1991; Chassin \& Barrera, 1993; Reich et al. 1993; Schuckit \& Smith, 1996; Alterman et al. 1998; Dierker et al. 1999), we demonstrated that offspring of alcoholic parents have an increased risk to drink more in adolescence. Both maternal and paternal alcoholism appear to increase the risk for children to shift into higher categories of alcohol consumption. Unlike previous researchers, we studied the effects of parental alcoholism on more than one specific drinking outcome (e.g. ever use); rather, we evaluated such effects within a cumulative lifetime use model that included simultaneously the effects on different levels of use (occasional, regular, hazardous use). This model showed that maternal AUD seems to affect specifically the transition from occasional into regular use, whereas paternal AUD also increases the risk for transition from regular into hazardous use. A speculative explanation for this paternal effect upon the transition into hazardous use could be that fathers show probably more excessive drinking than mothers and this may provide a role model for the hazardous use of alcohol in their offspring. Children whose parents are both affected have a more pronounced risk of developing higher drinking patterns during adolescence and young adulthood. This finding suggests that concordance for alcoholism among parents constitutes a particularly important risk factor for the escalation of alcohol use in offspring.

Our findings on associations between AUDs in parents and DSM-IV alcohol abuse and dependence in offspring confirm those reported previously (Sher et al. 1991; Reich et al. 1993; Mathew et al. 1993; Schuckit \& Smith, 1996; Merikangas et al. $1998 a, b)$. Offspring of parents in which at least one parent is affected by alcoholism have an increased risk of developing such a disorder. In agreement with Reich et al. (1993) and Dierker et al. (1999), we found no compelling evidence that the risks for alcohol abuse and dependence in offspring differ dramatically by number of affected parents. Parental concordance therefore seems not to be of crucial importance for the risk of alcohol abuse and dependence among offspring. Mechanisms that have been proposed to explain the observed parent-offspring association include genetic (Pickens et al. 1991; McGue et al. 1996; Heath 
et al. 1997; Prescott \& Kendler, 1999) and family environmental mechanisms (Hawkins et al. 1992; Swadi, 1999). Subsetting the analyses to mothers and fathers revealed significant findings only for the fathers. These findings seem to be in contrast to those of Bidaut-Russell et al. (1994), who observed an elevated risk for alcohol use disorders in daughters of alcoholic mothers. However, the fact that Bidaut-Russell and colleagues (1994) used a highly specific sample (women hospitalized for alcoholism) and controls without any parental history of alcoholism might explain this seeming inconsistency.

The age of onset findings demonstrate that having one or two affected parents increases the risk for first onset of hazardous use and dependence between the ages of 14-17. Having two affected parents additionally increases the risk to begin earlier with hazardous use and to have an earlier onset of alcohol abuse and dependence. These findings are similar to those reported by Hill and colleagues (Hill \& Muka, 1996; Hill et al. 1999, 2000), who found an earlier age of onset for drinking and for substance problems in youths with a high family density of alcoholism. Likewise, Tarter et al. (1997) showed that male adolescents with alcoholic fathers begin to drink earlier. Such age of onset characteristics in offspring of alcoholics are especially important considering research that has revealed that early initiation into alcohol use seems not only to be associated with an increased risk of onset of alcohol abuse and dependence (Grant \& Dawson, 1997; Nelson \& Wittchen, 1998), but also with an increased involvement in other drugs (Kandel et al. 1992).

With the exception that female offspring of affected mothers only have a higher (although not significant) risk for progression from occasional into hazardous use of alcohol than male offspring, our findings revealed no evidence for gender differences in associations, suggesting comparable impact of parental alcoholism in male and female offspring. Although our findings are consistent with those of Kendler et al. (1997), others have reported different patterns of sex-specificity (Pollock et al. 1987; Sher et al. 1991; Russell et al. 1990; Pickens et al. 1991; Bidaut-Russell et al. 1994; Thompson \& Wilsnack, 1994; Weinberg et al. 1994; McGue et al. 1996; Dierker et al. 1999). We assume that this variance of findings on sex-specificity in the literature is due to differences in sampling and assessment strategies, definitions of diagnostic status in parents and strategies of data analyses. Obviously, this issue warrants further consideration in future research.

\section{Limitations}

(1) One limitation of this study is the lack of direct interview data on all parents. Ideally, we should have interviewed mothers and fathers of all respondents directly. The assessment of familial psychopathology in such a large community sample necessarily requires the determination of what kind of information can be assessed. Taking design and economic considerations into account, we restricted ourselves to direct interviews with the parents of our younger cohort, but also collected additionally family history information from all respondents. Nevertheless, this strategy might have led to biased estimates in parents. One concern in this respect is the lower sensitivity of family history information (Andreasen et al. 1977, 1986; Thompson et al. 1982). To increase sensitivity, all available diagnostic information about alcohol use disorders in parents from the several sources was used. As reported by Kendler \& Roy (1995), family history information may also provide additional and complementary information about the 'true' history of psychopathology in individuals and should be seen not only as a substitute for direct diagnostic information. However, another concern is whether family history information is influenced by a respondent's diagnostic status (Kendler et al. 1991; Chapman et al. 1994). We examined whether respondents with alcohol use disorders demonstrate higher sensitivity for parental alcohol use disorders when compared to unaffected respondents and found no evidence for biased estimates. To protect for misleading results obtained by aggregating the two cohorts with different assessment of parental history, we tested all associations for interaction with age cohort. No differences in the associations were found.

(2) Not all respondents have passed through the entire risk period for onset of problematical drinking or alcohol abuse/dependence; thus the results can not yet be considered as robust. However, the inclusion of 'false-negative' cases 
(i.e. cases that have not yet developed the alcohol outcomes) probably resulted in an underestimation rather than an overestimation of associations.

(3) This paper focused exclusively on parental AUD in order to provide epidemiological data on the parent-offspring association for the observed alcohol outcomes in offspring. Clearly, the development of alcohol use and disorders must be seen as a complex interplay of multiple factors, and parental alcoholism constitutes only one of them (Hawkins et al. 1992; Chassin et al. 1993; Weinberg et al. 1998; Cichetti \& Luthar, 1999). In subsequent papers, we will investigate not only the extent to which other factors contribute to the development of alcohol problems in this population, but also how they contribute to their natural course (persistence or remission).

This work is part of the Early Developmental Stages of Psychopathology (EDSP) Study and is funded by the German Ministry of Research and Technology, project no. 01 EB 9405/6 and 01 EB 9901/6. Principal investigators are Dr Hans-Ulrich Wittchen and Dr Roselind Lieb. Current or former staff members of the EDSP group are Drs Kirsten von Sydow, Gabriele Lachner, Axel Perkonigg, Peter Schuster, Franz Gander, Michael Höfler and Holger Sonntag as well as Esther Beloch, Martina Fuetsch, Elzbieta Garczynski, Alexandra Holly, Barbara Isensee, Marianne Mastaler, Chris Nelson, Hildegard Pfister, Victoria Reed, Dilek Türk, Antonia Vossen, Ursula Wunderlich and Petra Zimmermann. Scientific advisors are Drs Jules Angst (Zurich), Jürgen Margraf (Basel), Günther Esser (Mannheim), Kathleen Merikangas (Yale, New Haven) and Ron Kessler (Harvard, Boston).

\section{REFERENCES}

Alterman, A. I., Bedrick, J., Cacciola, J. S., Rutherford, M. J., Searles, J. S., McKay, J. R. \& Cook, T. G. (1998). Personality pathology and drinking in young men at high and low familial risk for alcoholism. Journal of Studies on Alcohol 59, 495-502.

Andersen, P. K. \& Keiding, N. (1996). Survival analysis. In Advances in Biometry - 50 Years of the International Biometric Society (ed. P. Armitage and H. A. David), pp. 177-200. Wiley \& Sons: New York.

Andreasen, N. C., Endicott, J., Spitzer, R. L. \& Winokur, G. (1977). The family history method using diagnostic criteria: reliability and validity. Archives of General Psychiatry 34, 1229-1235.

Andreasen, N. C., Rice, J., Endicott, J., Reich, T. \& Coryell, W. (1986). The family history approach to diagnosis: how useful is it? Archives of General Psychiatry 43, 421-429.
Barbor, T. F., Kranzler, H. R. \& Lauerman, R. J. (1987). Social drinking as a health and psychosocial risk factor: Anstie's limit revised. In Research Advances in Alcohol, Vol. 5, (ed. M. Galanter), pp. 373-402. Plenum Press: New York.

Bidaut-Russell, M., Bradford, S. E. \& Smith, E. M. (1994). Prevalence of mental illness in adult offspring of alcoholic mothers. Drug and Alcohol Dependence 35, 81-90.

Chapman, T. F., Mannuzza, S., Klein, D. F. \& Fyer, A. J. (1994). Effects of informant mental disorder on psychiatric family history data. American Journal of Psychiatry 151, 574-579.

Chassin, L. \& Barrera, M. (1993). Substance use escalation and substance use restraint among adolescent children of alcoholics. Psychology of Addictive Behaviors 7, 3-20.

Chassin, L., Pillow, D. R., Curran, P. J., Molina, B. S. G. \& Barrera, M. (1993). Relation of parental alcoholism to early adolescent substance use: a test of three mediating mechanisms. Journal of Abnormal Psychology 102, 3-19.

Cichetti, D. \& Luthar, S. S. (1999). Developmental approaches to substance use and abuse. Developmental and Psychopathology 11, 655-656.

Dierker, L. C., Merikangas, K. \& Szatmari, P. (1999). Influence on parental concordance for psychiatric disorders on psychopathology in offspring. Journal of the American Academy of Child and Adolescent Psychiatry 38, 280-288.

Efron, B. \& Tibshirani, R. (1993). An Introduction of the Bootstrap. Chapman \& Hall: London.

Fahrmeier, L. \& Tutz, G. (1994). Multivariate Statistical Modelling Based on Generalized Linear Models. Springer: Berlin.

Grambsch, P. M. \& Therneau, T. M. (1994). Proportional hazard tests and diagnostics based on weighted residuals. Biometrika 81, 515-526.

Grant, B. F. \& Dawson, D. A. (1997). Age of onset of alcohol and its association with DSM-IV alcohol abuse and dependence: results from the National Longitudinal Alcohol Epidemiologic Survey. Journal of Substance Abuse 9, 103-110.

Greenland, S. (1995). Alternative models for ordinal logistic regression. Statistics in Medicine 13, 1665-1677.

Grove, W. M., Andreasen, N. C., McDonald-Scott, P., Keller, M. B. \& Shapiro, R. W. (1981). Reliability studies of psychiatric diagnosis. Archives of General Psychiatry 38, 408-413.

Hawkins, J. D., Catalano, R. F. \& Miller, J. Y. (1992). Risk and protective factors for alcohol and other drug problems in adolescence and early adulthood: implications for substance abuse prevention. Psychological Bulletin 112, 64-105.

Heath, A. C., Bucholz, K. K., Madden, A. F., Dinwiddie, S. H., Slutske, W. S., Bierut, L. J., Statham, D. J., Dunne, M. P., Whitfield, J. B. \& Martin, N. G. (1997). Genetic and environmental contributions to alcohol dependence risk in a national twin sample: consistency of findings in women and men. Psychological Medicine 27, 1381-1396.

Hill, S. Y. \& Muka, D. (1996). Childhood psychopathology in children from families of alcoholic female probands. Journal of the American Academy of Child and Adolescent Psychiatry 35, 725-733.

Hill, S. Y. \& Yuan, H. (1999). Familial density of alcoholism and onset of adolescent drinking. Journal of Studies on Alcohol 60, $7-17$.

Hill, S. Y., Locke, J., Lowers, L. \& Connolly, J. (1999). Psychopathology and achievement in children at high risk for developing alcoholism. Journal of the American Academy of Child and Adolescent Psychiatry 38, 883-891.

Hill, S. Y., Shen, S., Lowers, L. \& Locke, J. (2000). Factors predicting the onset of adolescent drinking in families at high risk for developing alcoholism. Biological Psychiatry 48, 265-275.

Holly, A. \& Wittchen, H.-U. (1998). Patterns of use and their relationship to DSM-IV abuse and dependence of alcohol among adolescents and young adults. European Addiction Research 4, $50-57$.

Kandel, D. B. (1984). Marijuana users in young adulthood. Archives of General Psychiatry 41, 200-209.

Kandel, D. B., Yamaguchi, K. \& Chen, C. (1992). Stages of progression in drug involvement from adolescence to adulthood: 
further evidence for the Gateway Theory. Journal of Studies on Alcohol 53, 447-457.

Kendler, K. S. \& Roy, M.-A. (1995). Validity of a diagnosis of lifetime major depression obtained by personal interview versus family history. American Journal of Psychiatry 152, 1608-1614.

Kendler, K. S., Silberg, J. L., Neale, M. C., Kessler, R. C., Heath, A. C. \& Eaves, L. J. (1991). The family history method: whose psychiatric history is measured? American Journal of Psychiatry 148, 1501-1504.

Kendler, K. S., Davis, C. G. \& Kessler, R. C. (1997). The familial aggregation of common psychiatric and substance use disorders in the National Comorbidity Survey: a family history study. British Journal of Psychiatry 170, 541-548.

Knop, J., Goodwin, D. W., Jensen, P., Penick, E., Pollock, V., Gabrielli, W., Teasdale, T. W. \& Mednick, S. A. (1993). A 30-year follow-up study of the sons of alcoholic men. Acta Psychiatrica Scandinavica 370, 48-53.

Lachner, G. \& Wittchen, H.-U. (1997). Münchener Composite International Diagnostic Interview-Familiengenetische Version. $M-C I D I-F G$. Max Planck Institut für Psychiatrie: Eigendruck.

Lachner, G., Wittchen, H.-U., Perkonigg, A., Holly, A., Schuster, P., Wunderlich, U., Türk, D., Garczynski, E. \& Pfister, H. (1998). Structure, content and reliability of the Munich-Composite International Diagnostic Interview (M-CIDI). Substance use sections. European Addiction Research 4, 28-41.

Lewinsohn, P. M., Rohde, P. \& Seeley, J. R. (1996). Alcohol consumption in high school adolescents: frequency of use and dimensional structure of associated problems. Addiction 91, 375-390.

Lieb, R., Isensee, B., Sydow, K. von, \& Wittchen, H.-U. (2000a). The Early Developmental Stages of Psychopathology Study (EDSP): I. Methodological update. European Addiction Research 6, $170-182$.

Lieb, R., Wittchen, H.-U., Höfler, M., Fuetsch, M., Stein, M. \& Merikangas, K. R. (2000 b). Parental psychopathology, parenting styles, and the risk of social phobia in offspring. A prospectivelongitudinal community study. Archives of General Psychiatry 57, 859-866.

Lish, J. D., Weissman, M. M., Adams, P. B., Hoven, C. W. \& Bird, H. (1995). Family psychiatric screening instrument for epidemiologic studies: pilot testing and validation. Psychiatry Research 57, 169-180.

McGue, M., Sharma, A. \& Enson, P. (1996). Parent and sibling influences on adolescent alcohol use and misuse: Evidence from a US-Adoption cohort. Journal of Studies on Alcohol 57, 8-18.

MacLean, C. J. (1988). Assessing changes in risk factor effect over multiple levels of severity. American Journal of Epidemiology 127, 663-672.

Mathew, R. J., Wilson, W. H., Blazer, D. G. \& George, L. K. (1993). Psychiatric disorders in adult children of alcoholics: data from the Epidemiologic Catchment Area Project. American Journal of Psychiatry 150, 793-800.

Merikangas, K. R., Weissman, M. M., Prusoff, B. A., Pauls, D. L. \& Leckman, J. F. (1985). Depressives with secondary alcoholism: psychiatric disorders in offspring. Journal of Studies on Alcohol 46, 199-204.

Merikangas, K. R., Dierker, L. C. \& Szatmari, P. (1998a). Psychopathology among offspring of parents with substance abuse and/or anxiety disorders: a highrisk study. Journal of Child Psychology and Psychiatry 39, 711-720.

Merikangas, K. R., Stevens, D. E., Fenton, B., Stolar, M., O'Malley, S., Woods, S. W. \& Risch, N. (1998b). Co-morbidity and familial aggregation of alcoholism and anxiety disorder. Psychological Medicine 28, 773-788.

Neff, J. A. (1994). Adult children of alcoholic or mentally ill parents: alcohol consumption and psychological distress in a tri-ethnic community study. Addictive Behaviors 19, 185-197.

Nelson, C. B. \& Wittchen, H.-U. (1998). DSM-IV alcohol disorders in a general population sample of adolescents and young adults. Addiction 93, 1065-1077.
Pandina, R. J. \& Johnson, V. (1990). Serious alcohol and drug problems among adolescents with a family history of alcoholism. Journal of Studies on Alcohol 51, 278-282.

Pickens, R. W., Svikis, D. S., McGue, M., Lykken, D. T., Heston, L. L. \& Clayton, P. J. (1991). Heterogeneity in the inheritance of alcoholism. A study of male and female twins. Archives of General Psychiatry 48, 19-28.

Pollock, V. E., Schneider, L. S., Gabrielli, W. F. \& Goodwin, D. W. (1987). Sex of parent and offspring in the transmission of alcoholism. A meta-analysis. Journal of Nervous and Mental Disease 175, 668-673.

Prescott, C. A. \& Kendler, K. S. (1999). Genetic and environmental contributions to alcohol abuse and dependence in a populationbased sample of male twins. American Journal of Psychiatry 156, 34- 40 .

Reed, V., Gander, F., Pfister, H., Steiger, A., Sonntag, H., Trenkwalder, C., Hundt, W. \& Wittchen, H.-U. (1998). To what degree does the Composite International Diagnostic Interview (CIDI) correctly identify DSM-IV disorders? Testing validity issues in a clinical sample. International Journal of Methods in Psychiatric Research 7, 142-155.

Reich, W., Earls, F., Frankel, O. \& Shayka, J. J. (1993). Psychopathology in children of alcoholics. Journal of the American Academy of Child and Adolescent Psychiatry 32, 995-1002.

Royall, R. M. (1986). Model robust confidence intervals using maximum likelihood estimators. International Statistical Review 54, 221-226.

Russell, M., Cooper, M. L. \& Frone, M. R. (1990). The influence of sociodemographic characteristics on familial alcohol problems: data from a community sample. Alcoholism: Clinical and Experimental Research 14, 221-226.

Saunders, J. B., Aasland, O. G., Amundsen, A. \& Grant, M. (1993). Alcohol consumption and related problems among primary care patients: WHO Collaborative Project on early detection of persons with harmful alcohol consumption. Addiction 88, 349-362.

Schuckit, M. A. \& Smith, T. L. (1996). An 8-year follow-up of 450 sons of alcoholic and control subjects. Archives of General Psychiatry 53, 202-210.

Sher, K. J., Walitzer, K. S., Wood, P. K. \& Brent, E. E. (1991). Characteristics of children of alcoholics: putative risk factors, substance use and abuse, and psychopathology. Journal of Abnormal Psychology 100, 427-448.

Spitznagel, E. L. \& Helzer, J. E. (1985). A proposed solution to the base rate problem in the kappa statistic. Archives of General Psychiatry 42, 725-728.

StataCorp. (1999). Stata Statistical Software: Release 6.0. Stata Corporation: College Station.

Swadi, H. (1999). Individual risk factors for adolescent substance use. Drug and Alcohol Dependence 55, 209-224.

Tarter, R. E., Kirisci, L. \& Clark, D. B. (1997). Alcohol use disorder among adolescents: impact of paternal alcoholism on drinking behavior, drinking motivation, and consequences. Alcoholism: Clinical and Experimental Research 21, 171-178.

Thompson, K. M. \& Wilsnack, R. W. (1994). Parental influence on adolescent drinking: modeling, attitudes, or conflict. Youth and Society 19, 22-43.

Thompson, W. D., Orvaschel, H., Prusoff, B. A. \& Kidd, K. K. (1982). An evaluation of the family history method for ascertaining psychiatric disorders. Archives of General Psychiatry 39, 53-58.

Weinberg, N. Z., Dielman, T. E., Mandell, W. \& Shope, J. T. (1994). Parental drinking and gender factors in the prediction of early adolescent alcohol use. International Journal of Addiction 29, 89-104.

Weinberg, N. Z., Rahdert, E., Cilliver, J. D. \& Glantz, M. D. (1998). Adolescent substance abuse: A review of the past 10 years. Journal of the American Academy of Child and Adolescent Psychiatry 37, 252-261.

Wittchen, H.-U. \& Pfister, H. (Eds.). (1997). DIA-X-Interviews: Manual für Screening-Verfahren und Interview; Interviewheft Längsschnittuntersuchung (DIA-X-Lifetime); Ergänzungsheft 
(DIA-X-Lifetime); Interviewheft Querschnittuntersuchung (DIA-X-12 Monate); Ergänzungsheft (DIA-X-12Monate); PC-Programm zur Durchführung des Interviews (Längsund Querschnittuntersuchung); Auswertungsprogramm. Swets \& Zeitlinger: Frankfurt.

Wittchen, H.-U., Perkonigg, A., Lachner, G. \& Nelson, C. B (1998a). Early developmental stages of psychopathology study (EDSP): Objectives and design. European Addiction Research 4, $18-27$.

Wittchen, H.-U., Nelson, G. B. \& Lachner, G. (1998b). Prevalence of mental disorders and psychosocial impairments in adolescents and young adults. Psychological Medicine 28, 109-126.

Wittchen, H.-U., Lachner, G., Wunderlich, U. \& Pfister, H. (1998c). Test-retest reliability of the computerized DSM-IV version of the Munich-Composite International Diagnostic Interview (M-CIDI). Social Psychiatry and Psychiatric Epidemiology 33, 568-578.

World Health Organization. (1990). Composite International Diagnostic Interview (CIDI): (a) CIDI-Interview (Version 1.0), (b) CIDI-User Manual, (c) CIDI-Training Manual (d) CIDI-Computer Programs. World Health Organization: Geneva. 